\title{
RACIONAIS MC'S SOB A PERSPECTIVA DO REALISMO ESTÉTICO DE GYORGY LUKÁCS
}

\section{RACIONAIS MC'S UNDER THE AESTHETIC REALISM PERSPECTIVE BY GYORGY}

Edson da Silva ${ }^{1}$

\begin{abstract}
Resumo: Este artigo trata de breve análise das narrativas nas letras da banda de RAP Racionais MC's, sob a ótica do realismo estético proposto por Gyorgy Lukács $(1970 ; 1966)$, para identificar elementos como a construção de personagens e situações típicas e a relação entre forma artística e vida social. Assinalando a produção da banda como uma forma de expressão das vicissitudes do realismo estético nas artes contemporâneas.

Abstract:This paper is a brief analysis of the narratives in the lyrics by the RAP band Racionais MC's under the aesthetic realism perspective proposed by Gyorgy Lukács $(1970 ; 1966)$, to identify such elements as the character construction and typical situations, and also the relationship between artistic form and social life. Marking the band's production as a way of expressing the aesthetic realism vicissitudes in contemporary arts.
\end{abstract}

Palavras-chave: RAP, Racionais MC's, Realismo, Lukács

Keywords: RAP, Racionais MC's, Realism, Lukács

\section{Introdução}

Durante o século XX, ou "o século da canção", como assinala Luiz Tatit (2004), a música apreendeu os elementos melódicos da fala cotidiana, como reproduziu cenas da vida comezinha brasileira. Surgida no final desta centúria da canção, no final da década de 1980, a banda de RAP Racionais MC's ${ }^{2}$ foi capaz de urdir as cenas típicas e dramáticas da vida social brasileira, marcadas pela opressão contra a população pobre, negra e da periferia das grandes cidades do país. Um dos mais importantes fenômenos da cultura brasileira contemporânea, suas músicas representam um periscópio sobre a realidade social do Brasil, através de um realismo estético capaz de urdir essas contradições societárias através de um universo ficcional.

Entendendo o RAP como a expressão musical do movimento hip-hop, como sigla para Rythm And Poetry, este trabalho parte da intrínseca relação entre música e literatura para utilizar a perspectiva de realismo estético herdada pelo teórico Gyorgy Lukács (1966; 1970), transpondo sua leitura da literatura para a letra da música, com o objetivo de urdir uma análise e interpretação das músicas "Eu tô ouvindo alguém me chamar", "Rapaz comum” e "Diário de um detento".

1 Mestre em Estudos Literários. Doutorando em Teoria da Literatura.

2 A banda é formada pelos MC's Mano Brown, Edi Rock e Ice Blue, que cantam as músicas. Também faz parte do grupo o DJ K1 Jay, responsável por criar as bases musicais. 
Com efeito, a obra do filósofo húngaro será utilizada para identificar, nas letras das músicas supracitadas, elementos próprios do realismo estético, como a construção de personagem e situação típicas, a negação à representação superficial e meramente mecânica da realidade social, a relação dialética entre forma artística e vida social, entre a subjetividade das personagens e objetividade do microcosmo social em que estão inseridas.

Em um primeiro momento, serão apresentadas reflexões que tangenciam a relação entre literatura e música e que tenham o RAP como objeto de análise (ROBERTS, 2008; DA CRUZ INÁCIO, 2008); em seguida, será apresentada a concepção de realismo estético de Gyorgy Lukács em cotejo com as letras dos Racionais MCs. Com esta transposição de aspectos da narrativa literária para a narrativa presente nas letras da música dos Racionais MC's, este trabalho busca enfatizar a persistência do realismo estético para além das obras literárias.

\section{O Realismo Estético de Racionais MC's}

Surgido no seio de hip-hop, um amplo movimento que comunga diversos formas de expressão, como a dança (break) e as artes plásticas (grafite), o RAP também se caracteriza pela sua insistência em veicular nas letras das músicas a vida nos espaços urbanos, pelo olhar de uma população marginalizada das benesses do capitalismo tardio.

Georgia Roberts (2008), ao analisar as letras de autores como 2PAC e Kanye West, apresenta o RAP como um renovador do realismo estético que surgiu na literatura ainda no século XIX:

Examines how the set of creative impulses initially ascribed to nineteenth-century American Realists, such as the artistic desire to portray objective truth and the primary focus on the everyday lives of ordinary people, continues to inform and shape presentday expectations and interpretations of narrative production (and in the case of this project, hip hop narrative production). (ROBERTS, 2018, p. 5).

Sendo os Racionais MC's é indiscutivelmente o grupo de RAP mais influente do Brasil, sua produção estética tornou-se objeto de variados estudos acerca do fenômeno do hip-hop no país. Neste sentido, o trabalho de Emerson Inácio (2008) é de suma importância para esta reflexão, uma vez que utiliza as letras do grupo de rap paulista "como um legítimo representante das tensões sociais, políticas e culturais que têm sido tematizadas na Literatura produzida no Brasil nos últimos anos." (p. 53).

Ensejada pelas sendas abertas pela sentença acima, esta breve análise de três músicas do grupo Racionais MC's busca trazer uma contribuição no sentido de pensar a literatura e música, 
utilizando os elementos da teoria e crítica literária para uma leitura das narrativas presentes nas letras do grupo de rap paulista, ao desenvolver uma análise das obras sob a ótica do realismo estético proposto pelo filósofo Gyorgy Lukács.

Sob esta perspectiva, o realismo de Racionais MC's não será interpretado como mero testemunho, como uma fotografia da paisagem urbana ou simples captação da epiderme dos fenômenos sociais. Essa diferença entre realismo estético e representação meramente informativa da vida social é o ponto em que Gyorgy Lukács diferencia o mero naturalismo do realismo estético.Evidentemente que a reflexão do pensador húngaro está assentada nas primeiras décadas do século XX e se debruça sobre o romance, porém, tendo em Racionais MC's músicas que formam uma narrativa, pode-se transpor esta concepção de realismo estético lukacsiano para uma leitura das letras da músicas da banda paulista.

Para Lukács (1966), o realismo estético somente é atingindo quando a narrativa é capaz de apresentar, na complexidade da sua particularidade e microcosmo ficcional, elementos essenciais da vida social em que a própria obra está inserida. A obra de arte poderá plasmar, no seu particular, o universal da problemática humana. Neste sentido, Racionais MC's criam um universo ficcional que não descreve, enumera, justapõe simplesmente acontecimentos das favelas paulistas, mas narra, seleciona, combina elementos desta realidade social no interior de suas narrativas.

Ainda dentro da sua concepção de realismo estético, Lukács aponta para os dois extremos que a narrativa realista não apresenta. O primeiro é a representação mecânica de um pretenso materialismo que não passa de um mero decalque da aparência dos fenômenos sociais. O segundo é o idealismo que rompe com as relações com o mundo objetivo pela representação fantasiadora. Ao romper com esses polos, o realismo estético é capaz de criar uma dialética entre o conteúdo e a forma:

A concepção dialética no interior do materialismo, portanto, insiste, por um lado, nesta unidade conteudística e formal do mundo do refletido, enquanto por outro lado, sublinha o caráter não mecânico e não fotográfico do reflexo (LUKÁCS, 1970, p. 148).

Trata-se de um processo de criação, de artifício, não de mero e maquinal artefato. O realismo não deve ser entendido somente como uma escola literária do século XIX, mas como um procedimento estético marcado pela dialética entre forma artística e vida social. Ao pensar este procedimento estético, Lukács refaz aquela velha proposição de Aristóteles, que diferencia o historiador do poeta, onde aquele diz o que aconteceu e, portanto, está preso ao fato; enquanto o último diz o que poderia acontecer, daí a capacidade de alargamento imaginativo de seu relato.

Em uma comparação entre músicas como "Eu tô ouvindo alguém me chamar” ou "Diário 
de um detento" e os relatos do telejornalismo policialesco, pode-se perceber esta distância já preconizada pelo Estagirita e reproduzida por Lukács e entender a dimensão do realismo estético e da particularidade da obra de arte.

Dentro da perspectiva herdada de Karl Marx, da arte enquanto reflexo da vida social, Lukács parte do princípio de que a arte fornece uma via de acesso à verdade objetiva da vida social. Porém, a arte não parte de um conceito universal para apreender os fenômenos sociais, como a ciência, mas é pela particularidade da obra, pela capacidade de urdir artisticamente o singular que a arte atinge a universalidade dos problemas humanos, sendo este o principal objetivo da obra de arte enquanto unidade inalienável de forma e conteúdo:

Esta meta consiste, en todo gran arte, en proporcionar una imagen de la realidad, en la que la oposición de fenómeno y esencia, de caso particular y ley, de inmediatez y concepto, etc., se resuelve de tal manera que en la impresión inmediata de la obra de arte ambos coincidan en una unidad espontánea, que ambos formen para el receptor una unidad inseparable. (LUKÁCS, 1966, p. 20).

Este ponto é de suma importância para uma compreensão da estética do RAP porque toca no potencial desta música no processo de conscientização da população marginalizada ${ }^{3}$. Dentro de uma teoria lukácsiana do realismo estético, pode-se observar este binômio entre ciência e arte de maneira muito evidente no RAP. Uma das músicas mais importantes da banda Racionais MC's, "Capítulo 4, versículo 3" é um exemplo de como o grupo logra urdir o reflexo da vida social, a música começa com dados da situação socioeconômica da população negra no Brasil:

$60 \%$ dos jovens de periferia sem antecedentes criminais já sofreram violência policial. A cada 4 pessoas mortas pela polícia, 3 são negras. Nas universidades brasileiras apenas $2 \%$ dos alunos são negros. A cada 4 horas, um jovem negro morre violentamente em São Paulo. Aqui quem fala é Primo Preto, mais um sobrevivente (RACIONAIS MC'S, 1997, grifo meu).

Apesar de trazer informações estatísticas e "oficiais" da vida social de que trata, a letra da música não deixa de apresentar uma tensão entre os dados e a subjetividade de quem fala enquanto sobrevivente dos mesmos números dramáticos do qual ele mesmo faz parte. Não se trata de uma discrição sociológica, dos resultados de uma pesquisa científica, mas de uma representação do processo dinâmico da vida social, na composição entre o objetivo e subjetivo. Sendo assim, a própria música aparece enquanto luta contra o silenciamento de quem sofre violências de todos tipos e não perde sua autonomia enquanto particularidade estética.

3 Vários trabalhos apontam para esta dimensão do RAP na conscientização da luta contra o racismo (BASTOS, 2000) e muitas vezes interpretam o próprio rapper como um intelectual orgânico. (SOUZA, 2019) 
A música dos Racionais MC's não recaí em mero sociologismo ou numa justaposição de dados científicos que coloca o discurso estético em segundo plano, ao romper a unidade deste enquanto particularidade estética. Essa relação de diferença e não de total aceitação com o reflexo científico é o que diferencia o realismo estético do naturalismo e suas bases positivistas.

Para Gyorgy Lukács, a obra de arte, enquanto forma de conhecimento específico da realidade social, retirará de elementos típicos, comuns da vida cotidiana da sociedade. Com efeito, não é possível, por meio da simples reprodução da vida cotidiana, uma construção realista de uma narrativa.

la capacidad del gran autor en cuanto a crear personajes típicos y situaciones típicas va mucho más allá de la observación justa de la realidad cotidiana. El conocimiento profundo de la vida no se limita nunca a la observación de lo cotidiano. Consiste, antes bien, en inventar, sobre la base de la comprensión de los rasgos esenciales, personajes y situaciones que en la vida cotidiana son absolutamente imposibles, pero que hacen con todo visibles, en agudización extrema de lo esencial, y muestran a la luz del efecto recíproco supremo y más puro de las contradicciones aquellas fuerzas y tendencias operantes cuyo efecto la vida cotidiana sólo muestra confusamente. (LUKÁCS, 1996, p. 134).

Por meio desta perspectiva teórica, pode-se ler as narrativas dos Racionais MC's não como um simples decalque de acontecimentos cotidianos da vida social da periferia brasileira. Trata-se de uma criação artística complexa, que apresenta personagens e situações típicas formadas pela própria dinâmica das contradições e fraturas no seio da sociedade.

Numa narrativa ficcional escrita ou musicada, a construção da personagem é um elemento fundamental da unidade de sua particularidade estética. No entanto, a lógica da personagem ficção possui um estatuto distinto de uma pessoa, uma vez que a personagem ficcional está encerrada dentro do microcosmo estético a qual pertence., enquanto uma pessoa historicamente circunscrita, dentro das contingencias da vida cotidiana, tudo na obra ficicional é necessário, cada elemento é parte de um todo, enquanto a vida cotidiana é marcada pela contingência do devir histórico. Logo, uma narrativa realista compõe a particularidade das personagens de forma a condensar as situações reais vividas por pessoas historicamente definidas, trata-se de retirar o típico, o universal das experiências aparentemente aleatórias da vida social.

"Eu tô ouvindo alguém me chamar", "Rapaz comum", "Diário de um detento, todas músicas pertencentes ao álbum Sobrevivendo no inferno [1997], são narrativas que plasmam as situações típicas, por meio de personagens típicos que, apanhadas em situações dramáticas, 
trazem à baila as contradições e forças motrizes que animam a vida social brasileira.

"Eu tô ouvindo alguém me chamar" trata-se de uma narrativa onde uma personagem sem nome, nos últimos minutos de sua vida, reflete sobre sua vida até o momento em que é assassinado em um bar da periferia de São Paulo. A narrativa é uma apresentação de um evento particular daquela estatística que aponta a morte de um jovem negro a cada quatro horas em São Paulo, apresentada na música 'Capítulo 4, versículo 3”.

O uso do fluxo narrativo compõe uma personagem complexa e evita qualquer mirada superficial sobre a particularidade deste elemento na narrativa. A rememoração deste narrador à beira da morte revela os últimos sete anos de sua vida, sua entrada na delinquência; a diferença com relação ao seu irmão; sua admiração a seu "professor do crime" Guina e seu arrependimento tardio. Toda esta conjuntura que forma o microcosmo da obra revela os aspectos das situações e personagens típicas na música.

O personagem-narrador e sem nome, rememora os últimos anos de vida enquanto faz aspectos de artifícios narrativos complexos, como o jogo de duplo entre ele e seu irmão: "Cuzão, fica você com seu sonho de doutor! / Quando acordar cê me avisa, morô? / Eu e meu irmão era como óleo e água / Quando eu sai de casa trouxe muita mágoa" (RACIONAISN, 1997). Esta relação do duplo, tão comum na narrativa literária ${ }^{4}$, é resolvida dentro das próprias forças motrizes da narrativa:

Meu sobrinho nasceu / Diz que o rosto dele é parecido com o meu / É, diz, um pivete eu sempre quis / Meu irmão merece ser feliz/ Deve estar a essa altura / Bem perto de fazer a formatura / Acho que é Direito, Advocacia / Acho que era isso que ele queria / Sinceramente eu me sinto feliz/ Graças a deus, não fez o que eu fiz. (RACIONAIS MC'S).

Como se vê, a conscientização que o RAP oferece não é uma apresentação meramente didática ou moralista, mas, por meio do procedimento realista, oferece uma experiência estética capaz de desvelar as engrenagens profundas da realidade objetiva. A apresentação do Guina, uma das personagens mais marcantes da obra dos Racionais MC's, pode ser entendida como um marca do próprio sistema de valores capitalistas que se introduzem na cultura de jovens pobres da periferia: "Puta aquele mano era foda / Só moto nervosa / Só mina da hora / Só roupa da moda". Apresentandose enquanto um professor do crime, uma espécie de superegoda personagem-narrador que se desligou da família, o Guina é o mandante de seu assassinato:

Eu conhecia aquela arma, é do Guina, eu sei! / Uma 380 prateada, que eu mesmo dei / Um moleque novato com a cara assustada (aí mano, o Guina mandou isso aqui pra você) / Mas

4 Veja-se "Esaú e Jacó”, de Machado de Assis; “O homem duplicado”, de José Saramago; “Budapeste”, de Chico Buarque; “Dois Irmãos”, de Milton Hatoum etc. 
depois do quarto tiro eu não vi mais nada”. (RACIONAIS MC'S).

Mas não se trata de simples maniqueísmo, onde o Guina é apresentado como simples delinquente, ele também aparece como uma vítima de uma vida miserável e violenta:

Lembro que um dia o Guina me falou / Que não sabia bem o que era amor / Falava quando era criança / Uma mistura de ódio, frustração e dor / De como era humilhante ir pra escola / Usando a roupa dada de esmola / De ter um pai inútil, digno de dó / Mais um bêbado, filho da puta e só / Sempre a mesma merda, todo dia igual / Sem feliz aniversário, Páscoa ou Natal / Longe dos cadernos, bem depois / A primeira mulher e o 22 / Prestou vestibular no assalto do busão / Numa agência bancária se formou ladrão / Não, não se sente mais inferior / Aí neguinho, agora eu tenho o meu valor. (RACIONAIS MC'S,).

O estatuto do protagonista e das personagens ao seu redor aponta para esta criação estética que revela o típico pelo adensamento das questões dramáticas que elas vivem e apresentam o ser social próprio da conjuntura em que estão inseridos. As contradições entre o narrador e seu irmão, a cultura do consumismo que exige um padrão de consumo que o jovem da periferia acessa por meio da delinquência, a construção do Guina como mentor intelectual e posteriormente como mandante da morte do narrador são elementos que trazem à bailaa complexidade da obra no quadro de um realismo estético e deixa claro que o trabalho artístico se revela pela particularidade mesma da obra de arte e não somente pelo seu conteúdo de denúncia da ação da violência sobre os mais pobres, caso contrário, a obra se tornaria apenas um mero decalque dos fenômenos cotidianos da engrenagem da vida social ou mero panfleto sociológico.

Como já fora dito, o realismo estético procura uma dialética entre forma e conteúdo sem recair no idealismo ou no materialismo mecânico. Já ficou demonstrado na breve análise de "Eu tô ouvindo alguém me chamar" como essa narrativa desnuda traços da vida social brasileira pela mediação da particularidade estética, sem buscar reproduzir mecanicamente a realidade objetiva que ela apresenta pela mediação estética.

Em “Rapaz comum”, narrativa também em primeira pessoa, os Racionais MC's criam um relato de uma personagem no seu post-mortem, como se fosse possível ler esta obra como uma espécie de continuação de "Eu tô ouvindo alguém me chamar", que termina a narrativa com a morte do próprio narrador. Mas não há uma guinada para qualquer tipo de idealismo no sentido de esfacelar os estatutos do ser social, elemento caro ao realismo estético. Como "Eu tô ouvindo alguém me chamar", a narrativa de "Rapaz comum" também começa com disparos sobre o narrador e o contexto em que esta personagem está demonstra a dramaticidade da narrativa: "A agonia, o desespero toma 
conta de mim. / Algo no ar me diz que é muito ruim. / Meu sangue quente / Não sinto dor. / A mão dormente / não sente o próprio suor" (RACIONAIS MC'S).

Diferente de "Eu tô ouvindo alguém me chamar", "Rapaz comum" adentra o fluxo de consciência no momento após a morte da personagem até seu sepultamento, trata-se de um RAP cantado com uma sucessão de versos muito mais rápida, criando uma narrativa vertiginosa ${ }^{5}$ durante toda música. Mas a estética dos Racionais não desemboca em um idealismo que enclausuraria a personagem de "Rapaz comum" em um mero drama particular, pelo contrário, sua morte é tão realisticamente típica como no narrador de "Eu tô ouvindo alguém me chamar". O próprio título da música não permite a visão isolada desta personagem, o adjetivo "comum" carrega esta marca do típico.

Suas últimas reflexões apontam tanto à tragicidade quanto a tipicidade de sua narrativa, irmanando-o com outras rapazes comuns: "Como eu podia imaginar / no velório de outras pessoas, hoje estou no lugar" (RACIONAIS MC'S). Mesmo no post mortem e com uma aproximação com o fantástico de uma personagem que acompanha seu próprio velório e enterro, o realismo estético impede um esvaziamento das tensões sociais. Mesmo na complexidade entre planos terrenos e alémmorte, não há uma guinada para fora do realismo estético, a condição de post mortem ainda prende o narrador aos problemas sociais que se desdobraram no seu assassinato:

Tão me chamando, meu tempo acabou. / Não sei pra onde ir! Não sei pra onde vou! / Qual que é? Qual que é? O quê que eu vou ser? / Talvez um anjo de guarda pra te proteger / Não sou o último nem muito menos o primeiro / A lei da selva é uma merda e você é o herdeiro! (RACIONAIS MC's).

Embora a personagem não saiba do seu futuro após o enterro, esta condição não a joga em uma elucubração sobre a vida ou morte, pelo contrário, suas últimas palavras representam sua consciência frente a uma ordem social em que está inserida. A lei da selva pode ser entendida como esta ordem que transpassa os planos do terreno e do além-vida sendo destrinchada pelo particular de um personagem construindo por um realismo estético na composição artística do ser social.

Diferente de "Eu tô ouvindo alguém me chamar" e "Rapaz Comum", a música "Diário de um detento" não é constituída porum narrador que se cala pelo seu assassinato. Trata-se de uma narrativa de um sobrevivente do massacre na Casa de Detenção de São Paulo, em 2 de outubro de $1992^{6}$.

O título da música chama atenção para a dialética entre o intimismo do "diário" e a falta de 5 Os samples utilizados como base das duas músicas atestam esta velocidade dos versos. Em "Eu tô ouvindo alguém me chamar", os autores utilizam a música lenta de Marvin Gaye "Poor Abbey Wals", ao passo que "Rapaz comum" faz uso da intensa "Hyperbolicsyllabicsesquedalymistic", de Isaac Hayes.

6 O Massacre do Carandirujá possui uma variedade de representações nas artes brasileiras. Foi tema da música "O Haiti é aqui”, de Caetano Veloso, do filme "Carandiru", de Hector Babenco, adaptação da narrativa de testemunho "Estação Carandiru", de Drauzio Varela. A vida na Casa de Detenção também se encontra em outros grupos de RAP, como Detentos do RAP e 509-E. 
identificação no termo "detento", por meio do realismo estético, a narrativa não recaí no idealismo de uma narrativa meramente subjetiva nem tampouco esconde a particularidade da personagem no "país das calças beges". A narrativa começa emulando a estrutura própria de um diário:

São Paulo, dia primeiro de outubro, de 1992, oito horas da manhã? / Aqui estou, mais um dia sob o olhar sanguinário do vigia / Você não sabe como é caminhar com a cabeça na mira de uma HK / Metralhadora alemã ou de Israel / Estraçalha ladrão que nem papel (RACIONAIS MC's).

No entanto, o narrador não somente descreve suas paisagens interiores, mas pensa enquanto membro daquela mesma sociedade que o marginaliza. Da passagem do dia primeiro para o dia 2 de outubro, dia do massacre, o narrador apresenta a sociedade em pleno funcionamento:

Ratatatá, mais um metrô vai passar / Com gente de bem, apressada, católica / Lendo jornal, satisfeita, hipócrita / Com raiva por dentro, a caminho do Centro / Olhando pra cá, curiosos, é lógico / Não, não é não, não é o zoológico" (RACIONAIS MC's).

Há todo um movimento que anima a sociedade que o detento consegue perceber desde as janelas de sua cela, criando assim uma relação entre o particular de sua mirada, privada de liberdade, e o geral dos movimentos da vida social. Mas "Diário de um detento" não é somente realista porque consegue criar a dialética entre o íntimo e o geral para falar da totalidade da vida social. Outro ponto importante nesta obra é sua intersecção entre narrativa histórica e ficcional, por meio de um testemunho de quem viveu empiricamente este massacre histórico. A música é composta por Mano Brown, principal integrante da banda, e Jucenir Prado, detento no momento da morte de 111 presidiários pela Polícia de São Paulo.

A narrativa do diário está em relação com a narrativa histórica através da apresentação da dinâmica da cidade de São Paulo. O que anima as forças motrizes da narrativa é uma ligação contínua entre o presídio e a rua, entre a subjetividade de quem escreve o diário e a objetividade da dinâmica da cidade ao redor do Carandiru.

Nos lances finais da narrativa, o plano do interior do presídio e do plano da vida para além dos muros aparecem sincronizado, o que aumenta a tensão horas antes do massacre:

Dois ladrões considerados passaram a discutir / Mas não imaginavam o que estaria por vir / Traficantes, homicidas, estelionatários / Uma maioria de moleque primário / Era a brecha que o sistema queria / Avisa ao IML, chegou o grande dia / Depende do sim ou não de um só homem / Que prefere ser neutro pelo telefone / Ratatatá, caviar e champanhe / Fleury foi almoçar, que se foda a minha mãe / Cachorros assassinos, gás lacrimogêneo / Quem mata 
Neste ponto da narrativa, diário e história estão imbricadas na construção do realismo estético. A indexação do governador à época, Luiz Antônio Fleury Filho,desvela a relação entre a narrativa historiográfica e o diário do detento, entre realidade social e a particularidade da arte. Mas, ainda dentro da relação entre microcosmo da obra e a forma da vida social, a música termina com uma reflexão acerca da condição das pessoas dentro daquela sociedade: "O ser humano é descartável no Brasil / Como modess usado ou Bombril / Cadeia? Guarda o que o sistema não quis / Esconde o que a novela não diz." (RACIONAIS MC'S).

Depois desta reflexão, no dia 3 de outubro, um dia depois do massacre, há um fechamento do diário, mas dentro da perspectiva do presidiário sem credibilidade: "Mas quem vai acreditar no meu depoimento? / Dia 3 de Outubro, diário de um detento." (RACIONAIS MC'S). O final da narrativa, transforma o diário em depoimento, mantêm a relação entre o íntimo e a objetividade histórica própria daquela relação essencial para um realismo estético.

\section{Considerações Finais: Racionais MC'se as persistências do realismo estético}

A leitura das letras da banda de maior expressão do RAP brasileiro permitiu a percepção de que o realismo estético tem suas vicissitudes na produção cultural contemporânea. A análise de "Eu tô ouvindo alguém me chamar", "Rapaz Comum" e "Diário de um detento" apresentou elementos essenciais para um realismo no sentido lukácsiano do termo, capaz de urdir uma complexa particularidade do fenômeno estético enquanto tal, em dialética com a dinâmica da vida social que a expressão artística representa.

Com efeito, este trabalho demonstrou que o realismo estético, assim como o pensava Lukács, não pode ser visto somente dentro do perímetro do romance social do século XIX, mas como um procedimento comum à construção artística e que, por extensão, repercute em outras formas de produção estética, como as letras dos Racionais MC's.

Se, como afirma Emerson Inácio (2008), o fenômeno do RAP pode ser entendido como uma produção onde a população marginalizada socialmente pode se entender e entender o mundo que o cerca, a análise feita neste ensaio permitiu interpretar este teor das letras dos Racionais MC's como uma herdeira da longa tradição realista, ao assinalar a particularidade da obra e sua relação dialética com a realidade objetiva que ela expressa e da qual também é expressão.

Ao transpor categorias de análises da literatura para as letras das músicas, esta encontro entre Lukács e Racionais solidifica a possibilidade de alargamento do olhar teórico-crítico, no sentido 
de urdir contatos entre as particularidades da música e da literatura e até contiguidades como, por exemplo, o método do realismo estético na composição das narrativas.

\section{Referências}

BASTOS, Pablo Nabarrete. "Contribuições históricas do Movimento Hip Hop para a luta contra o racismo e para a comunicação da juventude negra e periférica.” In: Revista de Comunicação Dialógica, 3. p. 65-80, 2020. Diponível em: https://www.e-publicacoes.uerj.br/index.php/rcd/article/view/50369 acesso em 26 out. 2020

DA CRUZ INÁCIO, Emerson. "Ser um preto tipo A custa caro": poesia, interculturalidade e etnia. In: Estudos de literatura brasileira contemporânea, 31. p. 53-68. 2008. Disponível em: https://www.redalyc.org/ pdf/3231/323127095003.pdf acesso em 25 out. 2020.

LUKÁCS, Gyorgy. Introdução a uma Estética Marxista: Sobre a Particularidade como Categoria da Estética. Tradução de Carlos Nelson Coutinho e Leandro Konder. 2a ed. Rio de Janeiro: Civilização Brasileira, 1970.

, Gyorgy. Problemas del Realismo. Tradução espanhola de Carlos Gerhard. Cidade do MéxicoBuenos Aires: Fondo de cultura econômica,1966.

RACIONAIS MC'S. Sobrevivendo no inferno. São Paulo: Zimbábue, 1997, 1 CD.

ROBERTS, Georgia. Who Killed It: Toward A Hip Hop Theory. 2018. 184 f.Tese (Doutorado em Filosofia)Universidade de Washington. Washington: 2008.

SOUZA, Juliana. O rapper como intelectual orgânico: um estudo etnomusicológico sobre $\mathrm{Nyl} \mathrm{MC}$ e a emancipação na sociedade brasileira. 2019. 138 f. Dissertação (Mestrado em Ciências Musicais) - Universidade Nova de Lisboa. Lisboa, 2019.

TATIT, Luiz. O século da canção. Ateliê Editorial, 2004. 